\section{Educação e desenvolvimento: uma parceria necessária na construção da emancipação sociocultural das populações indígenas*}

\author{
Marta Regina Brostolin**
}

Resumo: O presente trabalho aborda o tema desenvolvimento e educação, questiona a forma como ainda se apresentam projetos na área, preocupados com a produção e não com as pessoas, principalmente quando se trata de planos e estratégias de desenvolvimento voltados para as populações indígenas. Traz e analisa a concepção atual de desenvolvimento, cujo processo deve estar centrado no ser humano, na busca por uma maior qualidade de vida. Nessa perspectiva, o desenvolvimento implica a formação e educação da própria comunidade em matéria de cultura, capacidades, competências e habilidades que permitam a ela mesma, evidentemente com a ajuda de agentes e fatores externos, agenciar e gerenciar seu processo de desenvolvimento. Nesse contexto, a escola, por meio da educação escolar, pode ser um espaço de fronteira, fazendo as conexões entre mundos diferentes, ou seja, promotora de uma relação intercultural de respeito, autonomia e desenvolvimento.

Palavras-chave: educação; desenvolvimento; populações indígenas.

\begin{abstract}
The study in hand approaches the theme of development and education, questions the way in which projects are still presented in this area, concerned with the production and not the people, mainly when handling plans and strategies of development focussing on indigenous populations. The article brings up and analyses the current concept of development, which process should be centered on the human being, in search of better quality of life. In this perspective, development implies the training and education of the actual community in subjects of cultural, capacities, competences and abilities which permit the community itself, obviously with the help of agents and external factors, to be agents and manage their own process of development. In this context, the school, through education, can be a fronteir space, making the connections between different worlds, that is to say, promoting an intercultural relationship of respect, autonomy and development.
\end{abstract}

Key words: education; development; indigenous populations.
* Este trabalho é apenas um fragmento de uma pesquisa mais ampla, que busca investigar o papel da educação em programas de desenvolvimento local em populações indígenas, sendo seu objeto de estudo a população Terena residente em Mato Grosso do Sul.

** Psicopedagoga, mestre em Educação pela UCDB e doutora em Desenvolvimento Local pela Universidade Complutense de Madrid, com ênfase na Educação Indígena. Atua nos cursos de graduação e pós-graduação nas disciplinas Pedagógicas na UCDB e é pesquisadora do NEPPI/UCDB. brosto@ucdb.br 


\section{Introduzindo}

De acordo com Franco (2000, p.40), o desenvolvimento é o desafio mais presente que a humanidade enfrenta nos dias de hoje e, acrescenta ainda que, a maioria dos planos de desenvolvimento no mundo em desenvolvimento seria muito diferente se sua preocupação fosse com as pessoas e não com a produção. Para exemplificar essa questão afirma que "o Brasil foi um dos países que experimentou o maior crescimento econômico em passado recente e, no entanto, foi também um dos países do mundo que mais aumentou a distância entre crescimento econômico e desenvolvimento social". Para minimizar a situação e promover o desenvolvimento, segundo o autor, poder-se-ia fazer muitas coisas, mas o básico seriam, talvez, quatro coisas: gerar renda, multiplicar o número de proprietários produtivos, elevar o nível de escolaridade da população e aumentar o número de organizações da sociedade civil. Em suma, aumentar a produção e democratizar o acesso à riqueza e ao conhecimento.

Nessa ótica, uma estratégia de desenvolvimento humano deve ser descentralizada para envolver a participação da comunidade. Objetivos notáveis de desenvolvimento humano adotados em planos nacionais são freqüentemente frustrados porque aos beneficiários é dada pouca oportunidade de participação no planejamento e implementação.

Quando os projetos se destinam às populações indígenas, a situação é mais séria ainda. Os agentes promotores não levam em conta, suficientemente, as características culturais de cada povo, a forma tradicional de como organizam sua economia, ou então, transferem determinadas características de um grupo para outro, generalizando aspectos não generalizáveis, ou transferindo para os índios desejos e aspirações dos agentes não-índios.

Em Mato grosso do Sul, Estado que abriga a segunda maior população indígena do Brasil, ao redor de 60.000 índios ${ }^{1}$, é comum transferirem experiências dos Terena para os Guarani, partindo da falsa suposição de que os índios são fundamentalmente, iguais.

Bremen (1987) denuncia a tendência de agentes promotores de projetos de desenvolvimento, de considerar as comunidades indígenas como inseridas na mesma problemática da sociedade envolvente. São pobres e logo se inserem no amplo leque da marginalização social, sinalizando para a complexa e importante relação entre etnia e classe na América Latina.

$\mathrm{O}$ autor ainda questiona a validade de afirmações constantes em muitos projetos sobre a participação dos indígenas em sua elaboração. Ao analisar os argumentos indígenas para a concordância com as propos- 
tas em questão, percebe que os mesmos coincidem com as dos promotores. E ao analisar a concordância das comunidades indígenas quanto às propostas formuladas por agentes externos, percebe também o autor que a concordância ocorre não pelas razões que motivam o projeto, mas sim, para satisfazer suas necessidades imediatas. Contribui também para o fracasso de muitos projetos a falta de perspectiva para a pequena produção agrícola em geral, no contexto da política agrícola em vigor.

Nesse panorama, Lafer (1981) aponta algumas questões importantes para se entender esse fracasso: a necessidade de investimento para tornar a terra mais produtiva; uma administração descentralizada e a limitação das organizações locais e as imposições do sistema socioeconômico em relação ao financiamento e comercialização da produção.

No entanto, esses dados são de difícil compreensão para muitos povos indígenas, que necessitam chegar a uma certa ou até necessária adequação entre as exigências do mercado regional e as características / condições próprias das mesmas comunidades. Entretanto, ao procurarem soluções de problemas de curto prazo, acabam agravando ou criando problemas estruturais no sentido de provocarem maior dependência.

E essa dependência, (grifo nosso), não conduz a um desenvolvimento, pois segundo Martin (1999), em seu artigo Perspectivas de Desenvolvimento Local, “[...] o desenvolvimento local deve ser medido não em termo de aumento de capital, mas sim na medida em que reduz a dependência das comunidades locais e promove a melhoria na qualidade de vida". O autor ainda afirma que:

El desarollo local es el reactivador de la economia y dinamizador de la sociedad local, mediante el aprovechamiento eficiente de los recursos endógenos existentes en una determinada zona, capaz de estimular y diversificar su crecimiento económico, crear empleo, mejorar la calidad de vida de la comunidad local, siendo el resultado de un compromisso por el que se entiende el espacio como lugar de solidariedad activa. Lo que implica cambios de actitudes y comportamientos de grupos e individuos (Martin, 1999, p.3).

Podemos, então, entender Desenvolvimento Local como a apropriação pela comunidade e pelo ambiente dos benefícios econômicos dos processos de produção, por meio de um movimento participativo e articulado dos diversos agentes locais, criando sistemas sustentáveis que diminuam os desequilíbrios socioambientais do crescimento econômico; aumentem a oferta de trabalho; contribuam para o equilíbrio entre os planos territorial e social; coordenem e articulem políticas públicas de intervenção nas áreas de promoção econômica e ordenamento territorial e compatibilizem a promoção socioeconômica e a proteção do patrimônio natural e cultural. 


\section{Desenvolvimento humano, social e sustentável}

No processo de desenvolvimento, o alvo central é o ser humano como artesão de seu êxito ou fracasso, pois se requer que cada um, ao se tornar responsável pelo seu próprio progresso, influencie o seu entorno como fonte irradiadora de mudanças, de evolução cultural, de dinamização tecnológica e de equilibração meio-ambiental. Portanto, não se obtém desenvolvimento sem que se visualize o ser humano à luz da hierarquia de valores, em sua integridade como pessoa humana, membro construtivo de sua comunidade e agente de equilíbrio em seu meio geofísico. Enfim, o processo de transformação requerido pelo desenvolvimento implica necessariamente a evolução cônscia e autônoma do padrão de vida interno e externo de toda a população.

Em vista disso, a regra teórica básica, que fundamenta o capitalismo moderno, tem sido a de que todo desenvolvimento caracterize-se predominantemente como processo de transformação econômica com resultado imediato na área social, visando, por excelência, ao crescimento do padrão de vida externo da população no seio da qual o mesmo ocorre. Neste caso, a transformação social é vista como consequência da transformação econômica, o que não se comprova, do ponto de vista histórico, principalmente, nos países subdesenvolvidos e/ ou em vias de desenvolvimento. Pelo contrário, o aumento da riqueza econômica não concebida, produzido e partilhado pela base populacional desses países, dentre eles o Brasil, em vez de gerar e alavancar a qualidade de vida de sua gente a tem agravado de maneira brutal e contínua, evidentemente no sentido dos segmentos populacionais de base para os de elite.

Segundo Franco (2000), durante muito tempo se acreditou que o fator econômico era o único determinante do desenvolvimento, entretanto, atualmente, o desenvolvimento apresenta muitas dimensões: econômica, social, cultural, ambiental e físico-territorial, político-institucional e científico-tecnológica. Em suma, todas essas dimensões comparecem no processo de desenvolvimento, em conjunto, determinando-o ou, em particular, condicionando-o. Portanto, nos enfoques recentes do problema do desenvolvimento, o relevante consiste, talvez, em considerar não que o crescimento comporte aspectos sociais, mas que os avanços sociais que aparecem simplesmente como meta ou resultado final, sejam na realidade fatores contribuintes para o desenvolvimento e parte indispensável do processo de crescimento econômico, mediante o qual se pode atingir mais adiante melhores condições de bem-estar humano.

Nessa ótica, o que nos parece lógico é que as duas frentes de desenvolvimento - a social e a econômica - andem interativamente juntas, 
a social potencializando as pessoas para se tornarem sujeitos e agentes e a econômica ensejando sustentação material e apoio instrumental ao alavancamento da social no curso processual, disso resultando, aí sim, partilha da quantidade com qualidade em todas as dimensões de concretude da vida humana: saúde, higiene, salubridade, trabalho, segurança, educação, moradia, lazer, cultura, iniciativa, criatividade e congêneres.

Desta forma, a melhoria da qualidade de vida está condicionada à satisfação integral das necessidades básicas dos seres humanos do local, as quais podem ser resumidas em: subsistência (trabalho, alimentação, moradia, saúde, procriação, humor); proteção (segurança, direitos sociais, família); afeto (auto-estima, vontade, sensualidade, solidariedade, generosidade); entendimento (consciência crítica, curiosidade, instrução, capacidade de análise e interpretação); participação (disposição, diálogo, interação); ócio (despreocupação, tranqüilidade, tempo livre); criação (inventividade, imaginação, intuição, paixão); identidade (memória, coerência, reconhecer-se, diferença, compromisso) e liberdade (autonomia, autodeterminação, assumir-se, arriscar) (cf. Martin, 1999).

Portanto, uma política de desenvolvimento voltada para a satisfação das necessidades humanas, entendida em seu sentido mais amplo, transcende a racionalidade econômica convencional porque compromete o ser humano em sua totalidade. As relações que se estabelecem e que podem estabelecer-se entre necessidades e suas satisfações devem possibilitar a construção de uma filosofia e uma política de desenvolvimento autenticamente humanista.

Conceber as necessidades tão somente como carência, implica restringi-las ao aspecto puramente fisiológico, que é precisamente o âmbito em que a necessidade assume, com maior força e clareza, a sensação de falta de algo. Entretanto, na medida em que as necessidades surgem, motivando e mobilizando as pessoas, surgem também potencialidades que ainda podem chegar a ser recursos. Assim, entendidas as necessidades como carência e potência, revelam um processo dialético constituindo um movimento incessante.

Essa situação obriga a repensar o contexto social das necessidades humanas de uma maneira radicalmente distinta de como tem sido habitualmente pensado por planejadores sociais e promotores de políticas de desenvolvimento. Neste enfoque, torna-se necessário elaborar uma teoria das necessidades humanas para o desenvolvimento que nos sirva como instrumento de política e ação, pois quando se fala em desenvolvimento, fala-se em melhorar a vida das pessoas (desenvolvimento humano), de todas as pessoas (desenvolvimento social), das que estão vivas 
hoje e das que viverão amanhã (desenvolvimento sustentável).

Segundo Franco:

Sabemos mais ou menos quais são os ingredientes básicos do desenvolvimento humano e social sustentável. Sabemos que, em geral, para se desenvolver é preciso crescer, mas crescer sustentavelmente, produzir mais e melhor, sem inviabilizar a vida das gerações futuras distribuindo com mais equidade os frutos desse crescimento (2000, p.36).

\section{Educação e Desenvolvimento: uma parceria necessária na construção da emancipação sociocultural das populações indígenas}

O desenvolvimento em escala humana requer uma reestruturação e promoção de conhecimentos que despertem a consciência crítica e os instrumentos cognoscitivos necessários para contrapor as múltiplas formas de dependência. Essa promoção de conhecimentos se dá através da educação e, ao relacionar educação e desenvolvimento, não se deve pensar como processos independentes, que só se associam por imposições das circunstâncias históricas do presente. Embora o assunto, em si, pareça moderno e atual, o progresso social jamais deixou de apresentar definidas dimensões educativas. Se isso não tivesse acontecido, não se poderia sequer compreender o significado da educação no mundo moderno, ou seja, sua importância como fator de reconstrução social.

Diz-se que uma comunidade desenvolve-se quand o torna dinâmicas suas potencialidades. E, para isso acontecer, é necessário a reunião de vários fatores, dentre eles, o nível educacional da população. É preciso a existência de pessoas com condições de tomar iniciativas, assumir responsabilidades e empreender novos negócios, buscando apoio no poder local e em outros níveis de governo, pois desenvolver implica sempre em mudanças e participação da sociedade.

Portanto, o desenvolvimento local implica a formação e educação da própria comunidade em matéria de cultura, capacidades, competências e habilidades que permitam à ela mesma, evidentemente com a ajuda de todos os agentes e fatores externos, agenciar e gerenciar todo o processo de desenvolvimento da respectiva localidade, em vez de apenas participar de propostas ou iniciativas de desenvolvimento que venham de fora.

Em suma, o desenvolvimento local promove a dinamização da população, a valorização dos recursos locais, a criação de empregos e ajuda as mulheres e jovens, a implementação da economia social, a criação de empresas, a dinamização da cultura local e capacidade criativa e a 
investigação de novas tecnologias de desenvolvimento, porque, investigar é, antes de tudo, praticar o exercício da criatividade. Investigar é ver aquilo que os outros não vêem e pensar naquilo que os outros não pensaram. Enfim, investigar é a busca de novos enfoques para a participação real na criação de novas iniciativas de desenvolvimento (Ávila, 2000).

Podemos dizer que estamos diante de um processo de desenvolvimento local quando houver um processo de aproveitamento dos recursos e riquezas de um determinado local ou região, os quais podem ser valorizados e transformados pelo efetivo envolvimento da comunidade, resultando na melhoria da qualidade de vida da população através da geração de empregos, renda e acesso à saúde e educação.

Quando centramos como objetivo do desenvolvimento local, a qualidade de vida, é necessário investigar o que determina essa qualidade de vida de uma pessoa ou comunidade, principalmente, quando situada em outra tradição cultural. E, nesse caso, emerge com força a especificidade de uma proposta de desenvolvimento voltada para as comunidades indígenas. É fundamental atentar não apenas para as necessidades/demandas e bens econômicos ou recursos, mas para as formas internas de organização, suas estruturas políticas e sociais, valores, normas, espaço e cosmovisão. As economias indígenas articulam-se em torno das relações de parentesco, com divisão sexual de trabalho e voltadas para a geração de alimentos para consumo.

Cabe destacar que é sobre as economias indígenas que mais se faz sentir o impacto da perda dos territórios e a destruição dos recursos naturais, obrigando-as a passar de uma enorme diversidade e multiplicidade de alternativas de subsistência para uma ou duas, apenas. Portanto, o grande desafio para os projetos de desenvolvimento em comunidades indígenas é a dificuldade em articular os saberes indígenas com o conhecimento ocidental. A construção de alternativas econômicas nessas comunidades passa hoje, necessariamente, pela parceria entre os dois conhecimentos e a educação escolar pode ser o elo de ligação entre as duas culturas, sendo a escola um agente educativo, socializador e parceiro, oferecendo uma educação sintonizada com os direitos, interesses, necessidades e as especificidades da cultura indígena, transformando o ensino escolar em espaço de articulação de informações, práticas pedagógicas e reflexões dos próprios índios sobre seu passado, seu futuro, sobre seus conhecimentos, seus projetos e a definição de um lugar em um mundo globalizado.

Uma escola que faça com que o índio queira continuar a ser índio e não ficar desejando abandonar a aldeia, que ofereça uma educação do 
índio e não para o índio. Embora os textos legais, as políticas públicas e os discursos de seus representantes defendam uma educação intercultural e diferenciada para as populações indígenas, a realidade que se encontra ainda hoje nas aldeias é de uma escola que nada tem de diferente das demais escolas públicas situadas pelo interior do Brasil. Seu Projeto Político-Pedagógico ${ }^{2}$ foi elaborado pela equipe técnico-pedagógica das secretarias de educação municipais e, geralmente, são os mesmos para todas as escolas localizadas nas zonas rurais.

Portanto, atualmente, o grande desafio é transpor as barreiras impostas pela educação escolar para índio e construir uma educação indígena, que apresente concepções e propostas diferenciadas no que tange aos processos, meios e condições de transmissão, a natureza dos conhecimentos transmitidos e as funções sociais da educação. A escola para ser indígena, necessariamente, estaria propiciando o acesso aos saberes da cultura dominante, porém, antes disso, precisa estar priorizando a cultura local, os saberes, a organização social e a visão de mundo indígena, que antecedem aos da cultura dominante.

Para que aconteça essa inversão de prioridade no trabalho escolar, são muitas as dificuldades, tanto de ordem técnica, para promover a transformação e a sistematização dos conhecimentos indígenas em conteúdos escolares, quanto às resistências internas. A educação indígena, nessas circunstâncias, para se concretizar, precisa se fazer acompanhar de tais condições, se estabelecidas em bases associadas à cultura indígena, favorecerá o trabalho de auto-estima e, consequentemente, o apreço à cultura indígena.

Consideradas as condições e sendo a escola assimilada pela comunidade, esta tende a ser pensada a partir do ambiente sociocultural, isto é, além de propiciar a aquisição de conhecimentos da cultura dominante, na medida em que o papel da escola é debatido pela comunidade, a própria escola se torna espaço de "educação para a cultura", trabalhando, também como conteúdo escolar os saberes tradicionais, valendo-se de processos próprios de ensino e aprendizagem, tornando-se assim diferenciada e intercultural (Dalmolin, 2004).

Nesse contexto, a discussão não se finda, já não se estranha a vinculação da escola a projetos de vida da comunidade, projetos de futuro para as populações indígenas. A escola vai ganhando contornos mais definidos dentro do mundo indígena, os objetivos educacionais vão sendo formulados, visando ao reforço a valores culturais conciliados com os objetivos políticos da comunidade e movimentos indígenas. Embora a limitação maior ainda consista na necessária passagem do discurso para 
a prática, processo que depende de a escola ser pensada, construída e conduzida pelas comunidades, depende, também, de professores com formação nas devidas competências, isto é, no papel de professor e domínio dos saberes da cultura indígena e cultura nacional.

Quanto a esta questão, deve-se ressaltar o fato de os indígenas estarem buscando capacitação e ocuparem os cargos docentes, o que confere ao professor, compromisso e envolvimento com o contex to de luta pela conquista e garantia dos territórios, a busca por alternativas de sustentabilidade, fomentando e difundindo estratégias, debatendo direitos, enfim, a escola e, por meio dela, a educação, exercendo um papel político a partir de necessidades, interesses e potencialidades da comunidade que alavanquem o desenvolvimento.

Portanto, os argumentos acima e os depoimentos apresentados a seguir comprovam que na tentativa de buscar soluções para superarem as dificuldades enfrentadas atualmente, as populações indígenas estão buscando junto à educação escolar conhecimentos e instrumentos que, necessariamente, instruídos pelo olhar de sua cultura, contraponham as múltiplas formas de dependência, levando-os a emancipação social.

São declarações espontâneas de professores, alunos e pais da comunidade Terena da Aldeia Córrego do Meio, localizada na Terra Indígena Buriti, Município de Sidrolândia, Estado de Mato Grosso do Sul. Foram coletadas durante pesquisa de campo realizada em 2004, utilizando-se como instrumento o grupo de discussão e refletem o entendimento do interlocutor, naquele momento e, por meio delas, tais atores sociais apresentam como esta instituição, chamada escola, na atualidade e para o futuro, é reivindicada, seja como estratégia de resistência e emancipação sociocultural, seja para garantir condições de vida mais dignas.

Sobre o tema educação indígena os professores afirmaram:

[...] já se vê grandes avanços, todos nós sabemos que podemos ir além com ajuda externa, da nossa parte muito esforço.

[...] é a preparação do aluno para sua formação como pessoa e uma perspectiva de vida melhor, sem esquecer sua identidade, cultura, língua e costumes.

A educação indígena deve ser uma realidade entre os povos indígenas, sendo um ensino diferenciado no qual os seus valores culturais devem ser valorizados por ser etnias com peculiaridades definidas.

Percebe-se, pelos depoimentos, a compreensão do sentido político da escola e o papel da educação no enfrentamento e na resistência necessária da identidade cultural como estratégia de sobrevivência, com o debate sobre o que é preciso para garantir o futuro sociocultural e 
econômico da comunidade. A posição dos professores confirma o potencial de resistência do povo Terena, comprovando que são capazes de fazer uso da educação para afirmar sua identidade, sendo capazes também de avançar na adequação da educação escolar como instrumento que promova valores, autonomia e desenvolvimento.

Quando a discussão voltou-se para a relação escola e comunidade, a influência da mesma em pais e lideranças, as posições foram as seguintes:

A escola tem muita influência, pois a nossa comunidade acredita no trabalho que a escola está oferecendo [...];

É enorme em se tratando de conhecimento, pois uma escola era o sonho da comunidade;

A escola é muito importante para a nossa comunidade, pois é um fator decisivo na preparação do cidadão como agente transformador;

[...] sim, de preparar os alunos para serem cidadãos responsáveis.

As declarações, mais uma vez, refletem a importância política da escola no cotidiano e principalmente no imaginário da comunidade Terena de Córrego do Meio, exemplificado no trabalho de conscientização que o professor e a educação podem promover na comunidade. Ao cruzar as respostas dos pais com a dos professores, constatou-se que os mesmos são unânimes em reconhecer a importância da escola para a comunidade e demonstram isso através de depoimentos como:

É na escola que nossos filhos se preparam para o futuro;

A importância é em termo de preparar os alunos para ser um cidadão indígena capacitado;

$\mathrm{Sm}$, formar os alunos para ser cidadão consciente.

A resposta dos alunos de ensino médio coincide com a visão dos pais quando afirmam que:

A escola deixa nossa comunidade mais atualizada capacitando alunos índios a serem alguém na vida;

A importância da escola na comunidade é de ensinar mais os alunos para o melhoramento da comunidade;

A escola éimportante em nossa comunidade porque o estudoéa garantia do futuro de nossa comunidade, garantindo as condições de vida de cada índio Terena, tendo uma profissão e acompanhando a globalização; Hoje o estudo é muito importante porque sem ele nós não podemos alcançar nossos objetivos.

Uma análise das respostas apresentadas por amostragem demonstra que a comunidade representada aqui por pais e alunos confia e acredita no trabalho que vem sendo desenvolvido pela escola e seus professo- 
res, percebem e partilham de objetivos comuns voltados para uma educação intercultural e diferenciada, que contraponha as múltiplas formas de dependência e os prepare para viver em um mundo globalizado em uma posição de diálogo e respeito, atingindo um desenvolvimento e uma qualidade de vida maior. É pertinente, também ressaltar que, no contexto atual, a escola e por meio dela, a educação, pode contribuir dando suporte ao conjunto de ações pelo restabelecimento da dignidade, do bem viver, sendo um dos elementos chaves na promoção do desenvolvimento local.

Constata-se, ainda, que estão conscientes quanto a ser esse o grande desafio e a maior responsabilidade da escola indígena, quando enfrenta a burocracia das instituições governamentais responsáveis pela educação escolar indígena que estão mais preocupadas em determinar normas e averiguar seu cumprimento do que oportunizar a reflexão e discussão frente às necessidades e expectativas das comunidades indígenas que buscam construir uma educação centrada em um projeto que vai além da própria educação, ou seja, que trabalhe com uma noção ampliada de educação. Para isso, irá, necessariamente, envolver-se com questões fundamentais como a defesa e garantia das terras indígenas e a construção de alternativas de subsistência.

Os Terena, ao conquistar o direito de falar em seu próprio nome e, em nome de suas comunidades, superaram a condição de incapazes, imposta pelo preconceito da sociedade nacional. Resgatada a credibilidade em si mesmo, é preciso investir para destruir o temor do não indígena sobre a capacidade e o direito do indígena à educação, ao exercício de funções relevantes, privadas ou públicas, funções cujo exercício pressupõe competência, que consiste em uma estratégia do movimento para buscar relações de igualdade mantendo a identidade cultural indígena.

Por fim, com base no conjunto de reflexões apresentadas acima, pode-se afirmar que a distância entre a educação oferecida hoje nas escolas indígenas e os resultados esperados, sobretudo em termos de qualidade é muito grande, alguns limitadores estão relacionados a questões de infra-estrutura e técnica, à grande dificuldade na construção curricular como já foi mencionado anteriormente, mas, gradativamente, as populações indígenas pela intervenção política de seus movimentos, do confronto com as diferenças e com os saberes, construirão uma escola com características da comunidade e não do "branco", uma escola que ofereça uma educação diferenciada, que seja espaço de luta para que sejam atendidas as demandas da diversidade cultural, em suma, que leve a emancipação sociocultural, ou seja, ao desenvolvimento. 


\section{Notas}

${ }^{1}$ Conforme dados da FUNASA, 2006.

${ }^{2}$ Plano curricular que retrata a vida escolar, o que inclui as concepções filosóficas, sociológicas e pedagógicas que identificam e caracterizam a instituição e comunidade que nela participa de todas as atividades educativas.

\section{Referências}

ÁVILA, Vicente Fidélis. Formação Educacional em Desenvolvimento Local: relato de estudo em grupo e análise de conceitos. Campo Grande: Editora UCDB, 2000. BRANDÃO, Carlos Rodrigues. O que é Educação. São Paulo, Brasiliense, 1981. BREMEN, Volker. Fluentes de caz y recolecion modernas. Projetos de ayuda al desarollo destinados a los indigenas del Gran Chaco, s.l., 1987.

CEPAUR, F. D. H. Desarrolho e escala humana. Chile: Santiago, 1986. *max-neef DURKHEIM, Emile. Educação e Sociologia. São Paulo: Melhoramentos, 1978.

DALMOLIN, Gilberto. O papel da escola entre os povos indígenas: de instrumento de exclusão a recurso para a emancipação sociocultural. 2004. 267p (Tese de Doutoramento em Educação) Universidade de São Carlos.

FRANCO, Augusto. Porque precisamos de Desenvolvimento Local, Integrado e Sustentável. Brasília: Instituto de Política Millennium, 2000.

LAFER, Bothy Mindlin. A nova utopia indígena: os projetos econômicos. In: Antropologia e indigenismo na América Latina. São Paulo: Cortez, 1981.

LÓPES, Teresa. Servicio social y desarrollo local. In: Colegio de Asistentes Sociales. Chile, 1991.

MARTIN, Carpio. Nuevas realidades en el desarrollo local en España e Iberoamérica. In: Seminário Internacional sobre perspectivas de desarrollo local en Iberoamérica. Anais... Santiago de Compostela, 1999.

MAX-NEEF, Manfred et al. Desarrolho e escala humana. Devolopment Dialogue. CEPAUR. Uppsala, Suécia, 1986.

NERY, Neyde. A importância do animador no processo de desenvolvimento local. In: CONTAG - Confederação Nacional dos Trabalhadores na Agricultura. Programa de formação de lideranças e técnicos em desenvolvimento local sustentável. Módulo II. Brasília: CONTAG, 1998.

Recebido em 22 de janeiro de 2006 Aprovado para publicação em 05 de junho de 2006. 